\title{
Coumarin attenuates hepatic steatosis by down-regulating lipogenic gene expression in mice fed a high-fat diet
}

\author{
Min Young Um, Mi Kyeong Moon, Jiyun Ahn and Tae Youl Ha* \\ Division of Metabolism and Functionality Research, Korea Food Research Institute, 516 Baekhyun-Dong, Bundang-Gu, \\ Sungnam 463-746, Republic of Korea \\ (Submitted 6 July 2012 - Final revision received 17 October 2012 - Accepted 26 October 2012 - First published online 18 April 2013)
}

\begin{abstract}
Coumarin is a natural compound abundant in plant-based foods such as citrus fruits, tomatoes, vegetables and green tea. Although coumarin has been reported to exhibit anti-coagulant, anti-inflammation and cholesterol-lowering properties, the effect of coumarin on hepatic lipid metabolism remains unclear. In the present study, we evaluated the ability of coumarin to protect against hepatic steatosis associated with a high-fat diet (HFD) and investigated potential mechanisms underlying this effect. C57BL/6J mice were fed a normal diet, HFD and HFD containing $0.05 \%$ courmarin for 8 weeks. The present results showed that coumarin reduced weight gain and abdominal fat mass in mice fed the HFD for 8 weeks $(P<0 \cdot 05)$. Coumarin also significantly reduced the HFD-induced elevation in total cholesterol, apoB, leptin and insulin $(P<0.05)$. In the liver of HFD-fed mice, coumarin significantly reduced total lipids, TAG and cholesterol $(38,22$ and $9 \%$ reductions, respectively; $P<0 \cdot 05)$, as well as lipid droplet number and size. Additionally, thiobarbituric acid-reactive substance levels, as an indicator of hepatic steatosis, were attenuated by coumarin $(P<0 \cdot 05)$. Finally, coumarin suppressed the HFD-induced up-regulation in fatty acid synthase (FAS) activity, and the expression of sterol regulatory element-binding protein-1, FAS, acetyl-CoA carboxylase 1, PPAR $\gamma$ and CCAAT/enhancer-binding protein- $\alpha$ in the liver. Taken together, these results demonstrate that coumarin could prevent HFD-induced hepatic steatosis by regulating lipogenic gene expression, suggesting potential targets for preventing hepatic steatosis.
\end{abstract}

Key words: Coumarin: High-fat diet: Hepatic steatosis: Lipogenesis

Non-alcoholic fatty liver disease (NAFLD) is a progressive disorder that can lead to liver disease (e.g. fibrosis or cirrhosis) and cancer $^{(1)}$. NAFLD is strongly associated with insulin resistance and is estimated to occur in $70-100 \%$ of the obese population $^{(2)}$. Although the pathogenesis of NAFLD is not completely understood, excessive fat accumulation and oxidative stress in the liver appear to play a direct role in its initiation and development ${ }^{(2)}$. Furthermore, an excessive and inappropriate dietary fat intake causes insulin resistance, increases NEFA delivery to the liver and alters gene expression involved in lipid metabolism, which results in fat accumulation in the liver ${ }^{(3,4)}$. Therefore, current research is investigating whether phytochemicals in food exert beneficial effects on metabolism, such as preventing hepatic fat accumulation and improving insulin resistance.

Coumarin (1,2-benzopyrone) is a natural phenolic compound found in plant-based foods such as citrus fruits, tomatoes, vegetables and green tea. Coumarin has been reported to possess antibacterial, antiviral, vasodilatory, antimutagenic, antioxidant and anticancer activities ${ }^{(5)}$. In addition, coumarin has been shown to exert a protective effect against $\mathrm{CCl}_{4^{-}}$ induced hepatic injury in rats ${ }^{(6)}$. Hsu \& Yen $^{(7)}$ reported that coumaric acid inhibits the expression of PPAR $\gamma$ and CCAAT/ enhancer binding protein- $\alpha(\mathrm{C} / \mathrm{EBP} \alpha)$, and up-regulates adiponectin levels in 3T3-L1 adipocytes. In addition, coumaric acid exerts anti-obesity and lipid-lowering effects ${ }^{(8-10)}$. Although a number of studies have reported various biochemical actions of coumarin, the ability of coumarin to protect against high-fat diet (HFD)-induced hepatic steatosis in animals and the molecular mechanisms underlying the effects of coumarin have not yet been reported in detail.

Therefore, we evaluated the effect of coumarin on HFDinduced hepatic steatosis in mice. To determine the mechanisms responsible for its effect, we evaluated enzyme activities and gene expression involved in hepatic lipid metabolism.

Abbreviations: ACC1, acetyl-CoA carboxylase 1; C/EBP $\alpha$, CCAAT/enhancer binding protein- $\alpha$; CD, high-fat diet + coumarin $0 \cdot 05 \%$; FAS, fatty acid synthase; HFD, high-fat diet; ME, malic enzyme; NAFLD, non-alcoholic fatty liver disease; ND, normal diet; SREBP, sterol regulatory element-binding protein; TBARS, thiobarbituric acid-reactive substances; TC, total cholesterol.

*Corresponding author: T. Y. Ha, fax +82 31780 9225, email tyhap@krfi.re.kr 


\section{Experimental methods}

\section{Animals and diets}

Male C57BL/6J mice (4 weeks old) were purchased from Orient Bio. C57BL/6J mice are prone to obesity when fed a HFD, developing characteristics observed in human obesity ${ }^{(11)}$. After a 1-week adaptation period, mice were randomly divided into three groups ( $n 10$ per group) and fed a normal diet (ND), HFD or HFD containing $0.05 \%$ coumarin (CD) for 8 weeks. The HFD was prepared by supplementing the American Institute of Nutrition (AIN) 76 rodent diet with $15 \%$ fat (maize oil $5 \%$, coconut oil $3 \%$ and cocoa butter $7 \%$ ) and $0.5 \%$ cholesterol $(\mathrm{g} / 100 \mathrm{~g})$ and consisted of $31.2 \%$ fat, $18.5 \%$ protein and $50.3 \%$ carbohydrate. Feeding a HFD is crucial in the development of hepatic steatosis of the dietinduced obesity mouse model ${ }^{(11-13)}$. Coumarin was obtained from Sigma-Aldrich. The dose of coumarin was chosen from the results of our preliminary experiment, showing maximal inhibitory effects against increase in body fat and hepatic lipid accumulation (data not shown), and the results of previous animal studies ${ }^{(14,15)}$. The mice were housed individually and maintained at a controlled temperature $\left(22 \pm 1^{\circ} \mathrm{C}\right)$, humidity $(65 \pm 5 \%)$ and $12 \mathrm{~h}$ light $-12 \mathrm{~h}$ dark cycle. Body weight and food intake were recorded three times per week for 8 weeks. The mice were allowed ad libitum access to food and water.

At the end of experimental period, blood was obtained from the retro-orbital sinus of mice in the fasting state. Liver and adipose tissues (epididymal and retroperitoneal adipose tissue) were removed, weighed and immediately snap-frozen in liquid $\mathrm{N}_{2}$, and stored at $-80^{\circ} \mathrm{C}$ until analysed. The present study was approved by the Animal Care Committee of the Korean Food Research Institute and performed in compliance with the Guide for the Care and Use of Laboratory Animals.

\section{Blood analysis}

Serum levels of total cholesterol (TC), HDL-cholesterol, TAG, NEFA and glucose were determined using a commercial kit (Shinyang Chemical Company). Serum apoA1 and apoB levels were determined using a commercial kit (Nittobo). Insulin and leptin levels were quantified by ELISA (R\&D Systems).

\section{Analysis of hepatic lipids and thiobarbituric acid-reactive substances}

Hepatic lipids were extracted from the liver tissues according to the method of Folch et al. ${ }^{(16)}$. TC and TAG levels in the liver were determined using a commercial kit (Sinyang Chemical Company).

Hepatic lipid peroxidation was determined by evaluating the production of thiobarbituric acid-reactive substances (TBARS), according to the method of Ohkawa et al. ${ }^{(17)}$, in which the reaction of malondialdehyde (a product of lipid peroxidation) with thiobarbituric acid yields a compound that is quantified by measuring absorbance at $532 \mathrm{~nm}$.

\section{Hepatic and adipose tissue histology}

Liver and epididymal adipose tissue were removed and fixed with $10 \%$ buffered formalin. The paraffin-embedded samples were cut into $3-\mu \mathrm{m}$-thick sections on a microtome and stained with haematoxylin and eosin. Stained sections were analysed by light microscopy (BX50; Olympus), and digital images were captured. Adipocyte size was determined using the image analysis program Image $\mathrm{J}$ (National Institutes of Health; http://rsb.info.nih.gov/ij/).

\section{Lipogenic enzyme activities}

Hepatic tissue was homogenised in ice-cold buffer ( $\mathrm{pH} 7 \cdot 4$ ) containing $0.25 \mathrm{M}$-sucrose and $0.5 \mathrm{~mm}$-EDTA, and then centrifuged at $10000 \mathrm{~g}$ at $4^{\circ} \mathrm{C}$ for $30 \mathrm{~min}$. The supernatant was used to determine malic enzyme (ME) and fatty acid synthase (FAS) activities. ME activity was determined spectrophotometrically by monitoring the production of NADPH at $340 \mathrm{~nm}^{(18)}$. FAS activity was determined according to the procedures described by Gibson \& Hubbard ${ }^{(19)}$. Protein concentration was determined by the method of Lowry et al. ${ }^{(20)}$ using serum bovine albumin as the standard.

\section{Western blot analysis}

Hepatic tissues were homogenised in lysis buffer and then centrifuged at $13000 \mathrm{rpm}$ at $4^{\circ} \mathrm{C}$ for $20 \mathrm{~min}$. Total protein $(20 \mu \mathrm{g})$ was separated by $10 \%$ SDS-PAGE and then transferred to polyvinylidene fluoride membranes (Millipore). The membranes were blocked overnight with 5\% non-fat dry milk in Tris-buffered saline solution containing 0.05\% Tween-20 and then incubated for $4 \mathrm{~h}$ using rabbit polyclonal antibodies against sterol regulatory element-binding protein (SREBP)-1, FAS, acetyl-CoA carboxylase 1 (ACC1), C/EBP $\alpha, \operatorname{PPAR} \gamma$ and $\beta$-actin (1:1000; Santa Cruz Biotechnology, Inc.). $\beta$-Actin was used as the loading control. Immunoreactive proteins were detected by using the enhanced chemiluminescence (ECL) Western blotting detection system.

\section{RNA extraction and quantitative real-time RT-PCR analysis}

Total RNA was extracted from the liver tissue using the RNeasy Mini kit (Qiagen), according to the manufacturer's protocol. RT was carried out in a $20 \mu \mathrm{g}$ reaction mixture using $1 \mu \mathrm{g}$ total RNA and the Maxime RT PreMix Kit (iNtRON Biotechnology). The following primer pairs were used for real-time RT-PCR: SREBP-1c, 5'-GCAGCCACCATCTAGCCTG-3' and 5'-CAGCAGTGAGTCTGCCTTGAT-3'; FAS, 5'-GGAGGTGGTGATAGCCGGTAT- $3^{\prime}$ and $5^{\prime}$-TGGGTAATCCATAGAGCCCAG- $3^{\prime}$; ACC1, 5'-CTGCCGAAACATCTCTGGGA- $3^{\prime}$ and 5'-CTGCCGAAACATCTCTGGGA- $3^{\prime}$ and $\beta$-actin, $5^{\prime}$-GGCTGTATTCCCCTCCATCG- $3^{\prime}$ and $5^{\prime}$-CCAGTTGGTAACAATGCCATGT- $3^{\prime}$. Amplification was carried out using SYBR green PCR Master mix (Toyobo) and a Roche LightCycler 480 System (Roche Applied Science). Expression levels of SREBP-1c, FAS and ACC1 were normalised to $\beta$-actin. 
Table 1. Effect of coumarin on body weight and food intake

(Mean values with their standard errors, $n 10$ per group)

\begin{tabular}{|c|c|c|c|c|c|c|}
\hline & \multicolumn{2}{|c|}{ ND } & \multicolumn{2}{|c|}{ HFD } & \multicolumn{2}{|c|}{$C D$} \\
\hline & Mean & SE & Mean & SE & Mean & SE \\
\hline Initial body weight (g) & 17.97 & 0.21 & $18 \cdot 01$ & 0.22 & 17.95 & $0 \cdot 18$ \\
\hline Final body weight (g) & $26 \cdot 40^{\mathrm{a}}$ & 0.64 & $35 \cdot 16^{c}$ & 1.01 & $31.62^{b}$ & 0.68 \\
\hline Body weight gain $(\mathrm{g})$ & $8.43^{\mathrm{a}}$ & 0.64 & $17 \cdot 16^{\mathrm{c}}$ & 0.90 & $13 \cdot 67^{b}$ & 0.75 \\
\hline Food intake $(\mathrm{g} / \mathrm{d})$ & 2.93 & 0.11 & 3.31 & 0.14 & $3 \cdot 10$ & $0 \cdot 10$ \\
\hline
\end{tabular}

ND, normal diet; HFD, high-fat diet; CD, HFD + coumarin $0.05 \%$

a,b,c Mean values within a row with unlike superscript letters were significantly different $(P<0.05)$.

\section{Statistical analysis}

Statistical analysis was performed using the SPSS 14.0 package (SPSS, Inc.). Results are expressed as mean values with their standard errors. Groups were compared by one-way ANOVA and Duncan's multiple range test; $P<0.05$ was considered significant.

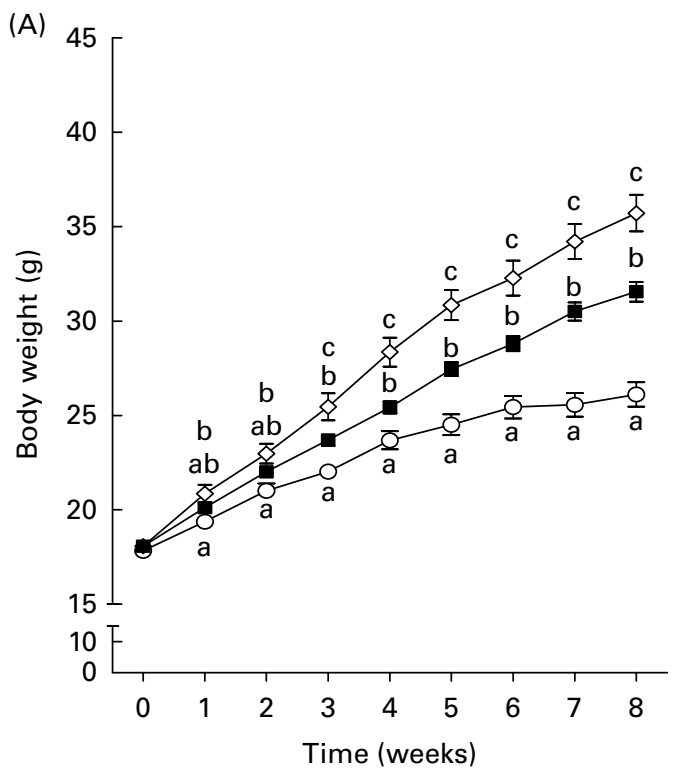

(C)

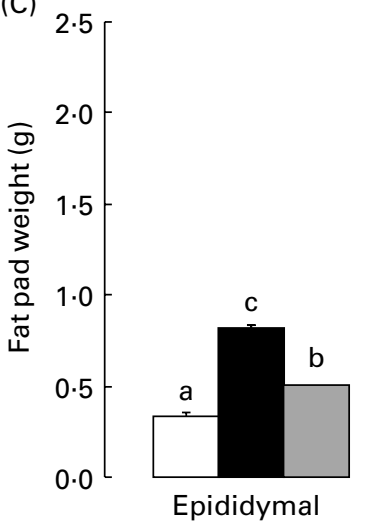

(D)

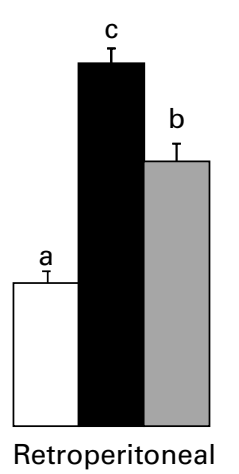

\section{Results}

Effects of coumarin on body weight, food intake and adiposity

Body weight was increased in mice fed the HFD, compared with mice fed the ND, but this increase was significantly

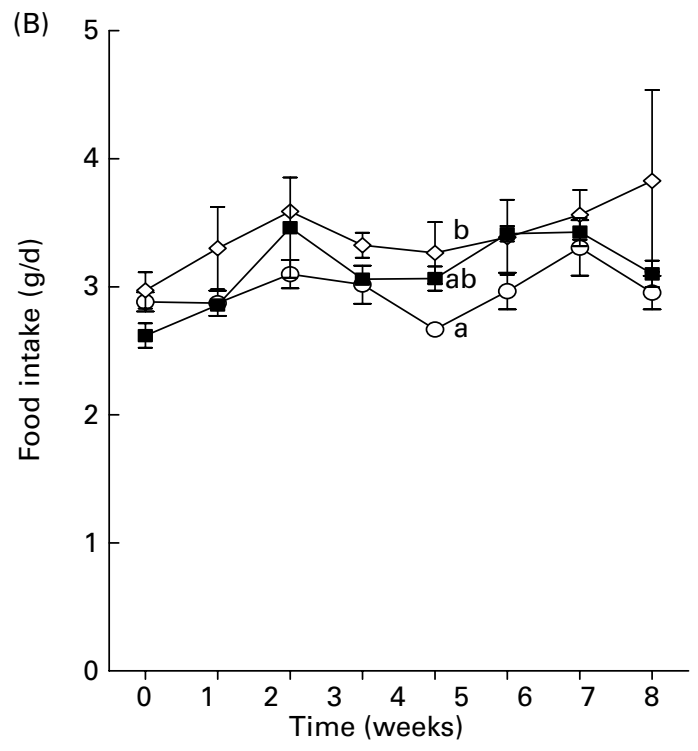

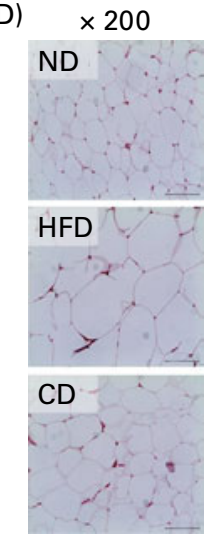
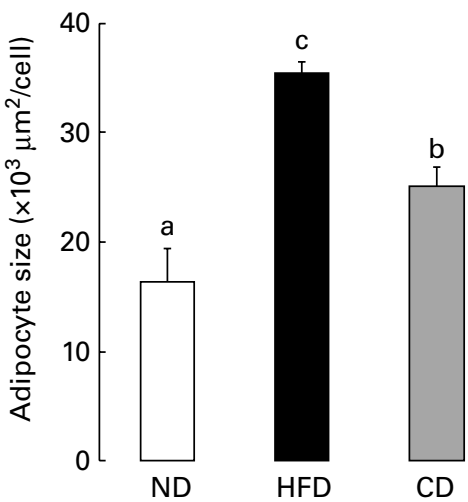

Fig. 1. Effects of courmarin on (A) body weight, (B) food intake, (C) abdominal fat pad weight and (D) epididymal adipocyte size in C57BL/6J mice fed experimental diets. Body weight gain and food intake were measured during the experimental period. Epididymal adipose tissues were isolated and stained with haematoxylin and eosin (H\&E). Adipocyte size was determined in H\&E-stained tissue (original magnification $\times 200$ ) by using Image $\mathrm{J}$ analysis software (National Institutes of Health). Values are means, with their standard errors represented by vertical bars ( $n 10$ per group). ${ }^{\mathrm{a}, \mathrm{b}, \mathrm{c}}$ Mean values with unlike letters were significantly different $(P<0.05$, Duncan's multiple range test). (A, B) $\diamond$, Normal diet (ND); -O-, high-fat diet (HFD); - - HFD containing 0.05\% coumarin (CD). (C) $\square$, ND; $\mathbf{m}, \mathrm{HFD}$; $\square$, CD. (A colour version of this figure can be found online at http://www.journals.cambridge.org/bjn). 
Table 2. Effect of coumarin on fasting serum lipid and lipoprotein levels in C57BL/6J mice fed an experimental diet for 8 weeks

(Mean values with their standard errors, $n 10$ per group)

\begin{tabular}{|c|c|c|c|c|c|c|}
\hline & \multicolumn{2}{|c|}{ ND } & \multicolumn{2}{|c|}{ HFD } & \multicolumn{2}{|c|}{$C D$} \\
\hline & Mean & SE & Mean & SE & Mean & SE \\
\hline TAG (mg/l) & $979 \cdot 7^{\mathrm{b}}$ & $56 \cdot 1$ & $894.9^{a, b}$ & 31.5 & $857 \cdot 3^{\mathrm{a}}$ & 13.5 \\
\hline NEFA $(\mu \mathrm{Eq} / \mathrm{l})$ & $1521 \cdot 17^{a}$ & 54.82 & $1518 \cdot 43^{\mathrm{a}}$ & $35 \cdot 38$ & $950 \cdot 82^{b}$ & $32 \cdot 20$ \\
\hline Total cholesterol $(\mathrm{mg} / \mathrm{l})$ & $902 \cdot 3^{\mathrm{a}}$ & $28 \cdot 1$ & $1561 \cdot 7^{\mathrm{C}}$ & 71.0 & $1403 \cdot 3^{\mathrm{b}}$ & $27 \cdot 9$ \\
\hline HDL-cholesterol (mg/l) & 622.9 & 11.7 & $808 \cdot 7$ & $86 \cdot 3$ & $790 \cdot 8$ & $56 \cdot 9$ \\
\hline Atherogenic index ${ }^{*}$ & $0.45^{a}$ & 0.04 & $1.01^{\mathrm{b}}$ & 0.18 & $0.81^{a, b}$ & 0.10 \\
\hline ApoA-1 (mg/l) & $128 \cdot 6$ & $5 \cdot 2$ & $118 \cdot 6$ & $8 \cdot 3$ & 117.5 & $6 \cdot 8$ \\
\hline ApoB $(\mathrm{mg} / \mathrm{l})$ & $207 \cdot 4^{a}$ & 0.9 & $282 \cdot 7^{\mathrm{b}}$ & $12 \cdot 1$ & $216 \cdot 9^{a}$ & 3.6 \\
\hline ApoB:ApoA-1 ratio & $1 \cdot 61^{\mathrm{a}}$ & 0.06 & $2.43^{\mathrm{b}}$ & 0.20 & $1.83^{\mathrm{a}}$ & 0.15 \\
\hline
\end{tabular}

ND, normal diet; HFD, high-fat diet; CD, HFD + coumarin $0.05 \%$

a,b,c Mean values within a row with unlike superscript letters were significantly different $(P<0.05)$

${ }^{*}$ Atherogenic index $=$ (total cholesterol-HDL-cholesterol)/HDL-cholesterol

reduced by coumarin supplementation in the $\mathrm{CD}$ group (Table 1 and Fig. 1(A)). However, food intake did not differ significantly among the experimental groups (Fig. 1(B)).

To determine whether the body weight gain in the HFD group was due to decreased fat accumulation, adipose tissue weight and adipocyte size were measured. As shown in Fig. 1(C), the weights of epididymal and retroperitoneal adipose tissues were 165 and $153 \%$ higher in the HFD group than in the ND group, but this increase was attenuated by coumarin supplementation (by 36.7 and $39.5 \%, P<0.05$ ). Similarly, the size of epididymal adipocytes was larger in the HFD group than in the ND group, but this effect was also attenuated by coumarin supplementation $(P<0 \cdot 05$, Fig. 1(D)). These results demonstrate that coumarin supplementation significantly decreased body fat accumulation.

\section{Effect of coumarin on serum lipid, insulin and leptin levels}

Next, the effects of coumarin on serum levels of lipids were evaluated. As shown in Table 2, mice fed the HFD had significantly higher serum TC and apoB levels than mice fed the ND. However, coumarin supplementation reduced serum TC, and mice in the CD group had apoB levels similar to that of the ND group. The atherogenic index and apoB:apoA ratio, which are sensitive biomarkers of CHD, were also elevated in the HFD group; however, these values were decreased in the CD groups. Furthermore, NEFA levels were significantly lower in the CD group than in the HFD group, but did not differ significantly between the ND and HFD groups. In contrast, HDL-cholesterol and TAG levels did not differ significantly among the experimental groups.

Finally, serum levels of insulin and leptin were significantly increased in the HFD group, but these values were reduced by 43.7 and $51.5 \%$, respectively, by coumarin supplementation (Fig. 2(A) and (B)). These results indicate that coumarin markedly improved blood lipid, insulin and leptin levels in HFD-fed mice.

\section{Effects of coumarin on hepatic lipid content and morphology}

A HFD is associated with steatosis and metabolic disorders ${ }^{(4)}$. Therefore, we investigated whether coumarin can protect against HFD-induced hepatic steatosis. We found that liver weight was significantly higher in HFD-fed mice than in NDfed mice, but this increase was reduced by coumarin supplementation (Fig. 3(A)). Histological analysis showed that HFD-fed mice developed hepatocellular micro- and macrovesicular vacuolation as a result of fat accumulation. These changes were ameliorated by coumarin supplementation (Fig. 3(B)). HFD-induced increases in hepatic total lipid, TAG and TC levels were also significantly decreased by coumarin (Fig. 3(C)). These results demonstrate that coumarin suppressed HFD-induced hepatic fat accumulation in the mice.

To determine whether the HFD-induced hepatic fat accumulation was associated with increased oxidative stress, we assessed the effects of coumarin on TBARS levels, an indicator of lipid peroxidation. TBARS levels were 2-fold higher in the HFD group compared with the ND group; however, the HFD-induced increase was reduced by $38 \%$ in the CD group (Fig. 3(D)). These findings suggest that coumarin can ameliorate hepatic oxidative stress associated with NAFLD.

\section{Effects of coumarin on lipid-regulating enzyme activities in the liver}

To determine the mechanism by which coumarin suppresses fat accumulation in the liver, we evaluated the activities of hepatic lipid-regulating enzymes. We found that FAS activity was elevated in the HFD group compared with the ND group, but that coumarin significantly decreased FAS activity (Table 3). In contrast, ME activity did not differ significantly between the ND and HFD groups, but was lower in the CD group compared with the other experimental groups.

\section{Effects of coumarin on lipogenic gene expression in the liver}

To further clarify the molecular mechanisms underlying the effects of coumarin on HFD-induced hepatic steatosis, we evaluated the expression of lipogenesis-related genes by Western blot analysis and quantitative RT-PCR. As shown in 

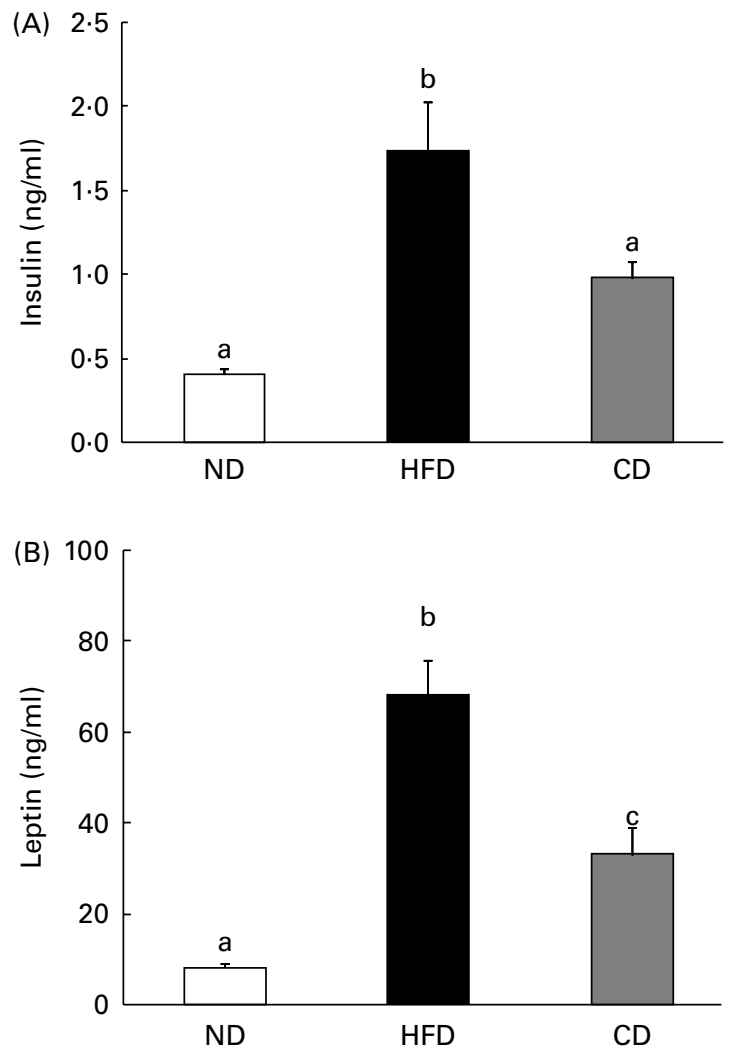

Fig. 2. Effect of coumarin on serum concentrations of $(A)$ insulin and $(B)$ leptin in C57BL/6J mice fed experimental diets for 8 weeks. Values are means, with their standard errors represented by vertical bars ( $n 10$ per group). $\mathrm{a}, \mathrm{b}, \mathrm{c}$ Mean values with unlike letters were significantly different $(P<0.05$, Duncan's multiple range test). ND, normal diet; HFD, high-fat diet; CD, HFD containing $0.05 \%$ coumarin.

Fig. 4, SREBP-1c protein and mRNA levels were higher in the HFD group than in the ND group. Accordingly, expression of SREBP-1c target genes FAS and ACC1 were also up-regulated in the HFD group. However, protein levels of SREBP-1c, FAS and ACC1 were reduced in the CD group.

Protein levels of PPAR $\gamma$ and $\mathrm{C} / \mathrm{EBP} \alpha$, regulators of lipogenesis and insulin signalling, were also increased in the HFD group, but were reduced by coumarin supplementation. Taken together, these findings suggest that coumarin regulates hepatic lipid metabolism by modulating the expression of lipogenic genes.

\section{Discussion}

In the present study, we examined the effect of coumarin on HFD-induced fat accumulation in $\mathrm{C} 57 \mathrm{BL} / 6 \mathrm{~J}$ mice. Hepatic steatosis is usually observed in obese subjects. Several studies demonstrated that hepatic steatosis is closely related to body adiposity, indicating that reducing fat mass could be beneficial in obesity-related hepatic steatosis ${ }^{(12,13)}$. In the present study, the present results show that increased body weight gain and adipose fat mass in HFD-fed mice were significantly lowered by coumarin supplementation. Fat reduction is typically accomplished by decreasing food intake, but we found that food intake was similar among the experimental groups in the present study. Consistent with these results, the weight of epididymal fat was lower in mice that received coumarin supplementation compared with the HFD group. Leptin is an adipocyte-derived hormone that plays a key role in appetite regulation and energy expenditure, and leptin levels correlate strongly with body fat in HFD-fed mice ${ }^{(21)}$; therefore, serum leptin levels are used as a marker of body fat accumulation. We found that coumarin significantly reduced serum leptin levels that were increased by the HFD. These results suggest that coumarin supplementation can inhibit HFDinduced body weight gain and fat accumulation.

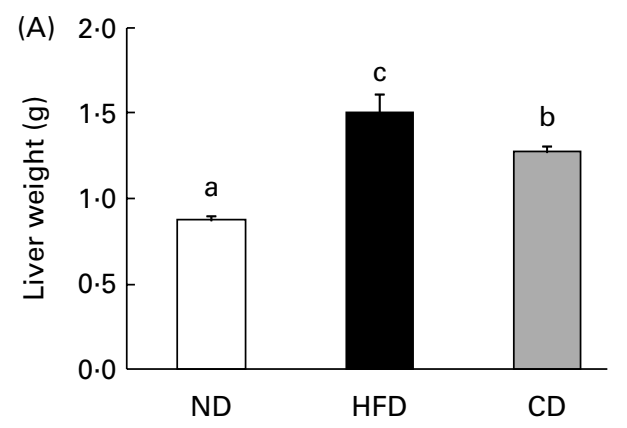

(B)
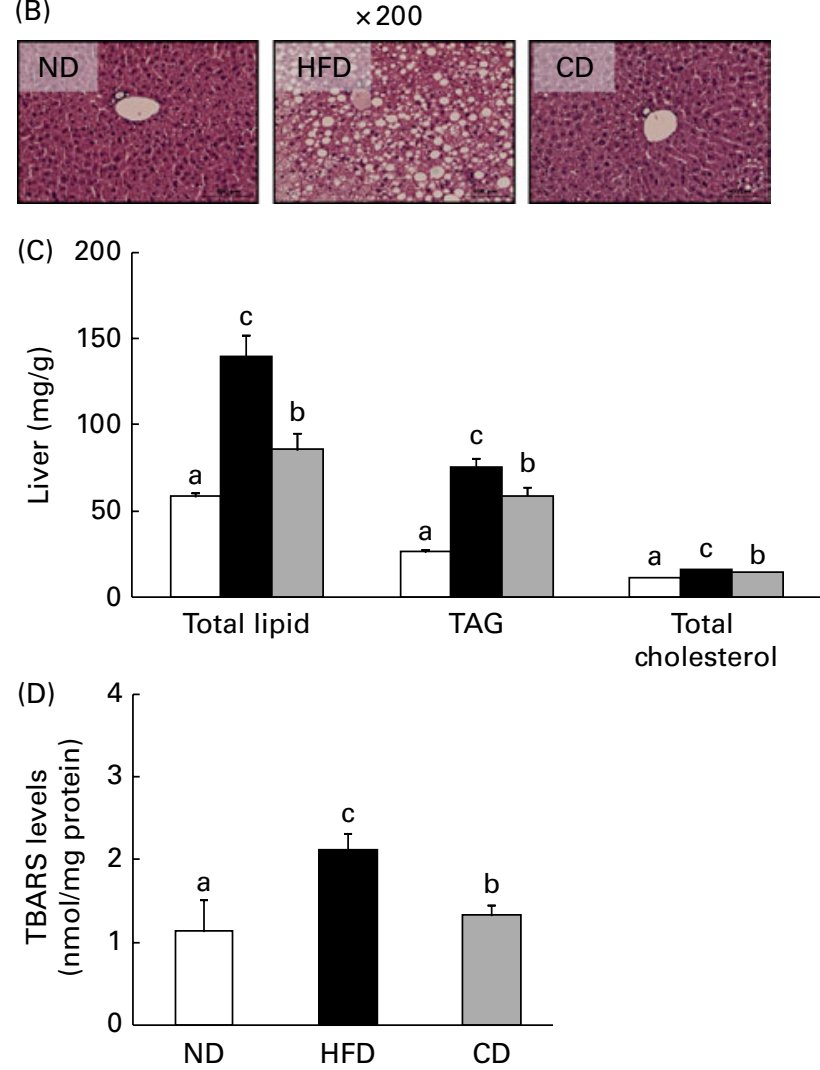

Fig. 3. Coumarin alleviates high-fat diet (HFD)-induced fat accumulation in the liver. (A) Liver weight, (B) representative haematoxylin and eosin-stained liver section, (C) hepatic lipid concentrations and (D) hepatic thiobarbituric acid-reactive substance (TBARS) levels in mice fed experimental diets for 8 weeks. Values are means, with their standard errors represented by vertical bars ( $n 10$ per group). ${ }^{a, b, c}$ Mean values with unlike letters were significantly different $(P<0.05$, Duncan's multiple range test). $\square$, Normal diet (ND); $\mathbf{a}$, HFD; $\square$, HFD containing $0.05 \%$ coumarin (CD). (A colour version of this figure can be found online at http://www.journals.cambridge.org/bjn). 
Table 3. Effects of coumarin on the activities of lipid metabolism enzymes in C57BL/6J mice fed an experimental diet for 8 weeks

(Mean values with their standard errors, $n 10$ per group)

\begin{tabular}{|c|c|c|c|c|c|c|}
\hline & \multicolumn{2}{|c|}{ ND } & \multicolumn{2}{|c|}{ HFD } & \multicolumn{2}{|c|}{$C D$} \\
\hline & Mean & SE & Mean & $\mathrm{SE}$ & Mean & $\mathrm{SE}$ \\
\hline $\begin{array}{l}\text { Fatty acid synthase (nmol/min per } \mathrm{mg} \text { protein) } \\
\text { Malic enzyme ( } \mathrm{nmol} / \mathrm{min} \text { per } \mathrm{mg} \text { protein) }\end{array}$ & $\begin{array}{r}6.95^{\mathrm{a}} \\
64.93^{\mathrm{b}}\end{array}$ & $\begin{array}{l}0.53 \\
6 \cdot 38\end{array}$ & $\begin{array}{r}9 \cdot 26^{\mathrm{b}} \\
58 \cdot 87^{\mathrm{b}}\end{array}$ & $\begin{array}{l}0.78 \\
4.90\end{array}$ & $\begin{array}{r}5 \cdot 45^{\mathrm{a}} \\
33 \cdot 70^{\mathrm{a}}\end{array}$ & $\begin{array}{l}0.25 \\
5.76\end{array}$ \\
\hline
\end{tabular}

ND, normal diet; HFD, high-fat diet; CD, HFD + coumarin $0.05 \%$.

${ }^{\mathrm{a}, \mathrm{b}}$ Mean values within a row with unlike superscript letters were significantly different $(P<0.05)$

Recent studies have documented a close relationship between NAFLD and hyperlipidaemia ${ }^{(22,23)}$, which results in lipid and NEFA accumulation in hepatocytes, causing liver damage. Although TAG levels were similar among the experimental groups in the present study, coumarin supplementation significantly reduced serum levels of TC, NEFA and apoB. These results are consistent with the findings of $\mathrm{Hsu}$ et $a l^{(10)}$, who reported that 8 weeks of coumaric acid supplementation suppressed HFD-induced increases in serum TAG and TC in obese rats. Similarly, Yuce et $a l^{\left({ }^{(8)}\right.}$ reported that serum TC was lowered by 7,8-dihydroxy-3-(4-methylphenyl) coumarin in rats. It is plausible that the normalisation of serum lipid levels in the CD group prevented the accumulation of hepatic lipids.

The liver plays a central role in lipid metabolism. Results of human and animal studies indicate that hepatic steatosis is associated with accumulation of the end products of de novo fatty acid synthesis ${ }^{(24,25)}$. In the present study, histological analysis showed that the HFD caused a significant increase in the number of lipid droplets in the liver, which was ameliorated by coumarin supplementation. We also found that coumarin significantly reduced total lipids, TAG and TC levels in the liver and decreased the activity of enzymes involved in hepatic fatty acid synthesis (i.e. FAS and ME). FAS catalyses the synthesis of long-chain SFA from acetyl-CoA and malonyl-CoA in the presence of $\mathrm{NADPH}^{(11)}$, and $\mathrm{ME}$ is a lipogenic enzyme involved in supplying NADPH for fatty acid biosynthesis ${ }^{(26)}$. Reducing hepatic FAS and ME activity limits the availability of the long-chain fatty acids required for TAG synthesis. Thus, our finding that coumarin reduced hepatic FAS and ME activity in HFD-fed mice probably accounts for the decreased hepatic lipid accumulation.

The present study showed that coumarin altered hepatic lipid metabolism and the expression of genes involved in these processes. SREBP-1c is a transcription factor that regulates genes related to lipid synthesis. Its deficiency can prevent hepatic steatosis in ob/ob mice, and its overexpression leads to the up-regulation of ATP citrate lyase, ACC, FAS and stearoyl-CoA desaturase- $1^{(27)}$. We found that the HFD-induced up-regulation of SREBP-1c was markedly suppressed by coumarin, along with expression of its target genes, FAS and ACC1. These results suggest that coumarin reduced hepatic lipid accumulation by regulating SREBP-1c, thereby reducing the expression of fatty acid synthesis-related genes.
PPAR $\gamma$ and $\mathrm{C} / \mathrm{EBP} \alpha$ are involved in fat accumulation in hepatocytes. Specifically, PPAR $\gamma$ is a ligand-activated transcriptional factor required for the differentiation of preadipocytes into mature adipocytes. Yu et al. ${ }^{(28)}$ reported that liver-specific disruption of PPAR $\gamma$ in leptin-deficient mice improves fatty liver and steatosis. In addition, PPAR $\gamma$ expression in the liver is increased by $\mathrm{HFD}^{(29)} . \mathrm{C} / \mathrm{EBP} \alpha$ also plays an important role in hepatic lipid metabolism. Matsusue et $a l .{ }^{(30)}$ found that $\mathrm{C} / \mathrm{EBP}-\mathrm{knockout}$ mice had significantly reduced TAG levels and down-regulated expression of lipogenic genes, despite obesity. Finally, PPAR $\gamma$ and $\mathrm{C} / \mathrm{EBP} \alpha$ are up-regulated and subsequently activate the lipogenic target genes (cluster of differentiation 36 (CD36), lipoprotein lipase and acyl-CoA synthetase, etc.) in the liver of obese

(A)
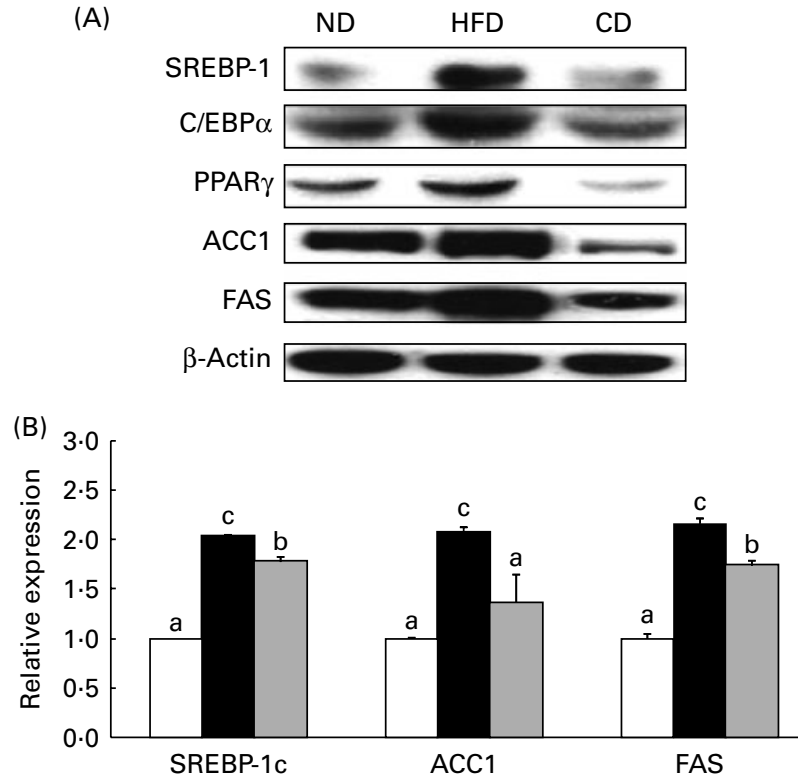

Fig. 4. Effect of coumarin on the expression of (A) protein and (B) mRNA involved in lipogenesis and adipogenesis in the liver of mice fed experimental diets. Protein levels were determined by Western blot analysis and normalised to $\beta$-actin. The mRNA levels of target genes were determined by realtime quantitative RT-PCR and normalised to $\beta$-actin. Values are means, with their standard errors represented by vertical bars ( $n 10$ per group). ${ }^{\mathrm{a}, \mathrm{b}, \mathrm{c}}$ Mean values with unlike letters were significantly different $(P<0.05$, Duncan's multiple range test). $\square$, Normal diet (ND);, , high-fat diet (HFD); $\square$, HFD containing $0.05 \%$ coumarin (CD). SREBP-1, sterol regulatory elementbinding protein-1; $\mathrm{C} / \mathrm{EBP} \alpha, \mathrm{CCAAT} / \mathrm{enhancer}$ binding protein- $\alpha ; \mathrm{ACC} 1$, acetyl-CoA carboxylase 1; FAS, fatty acid synthase. 


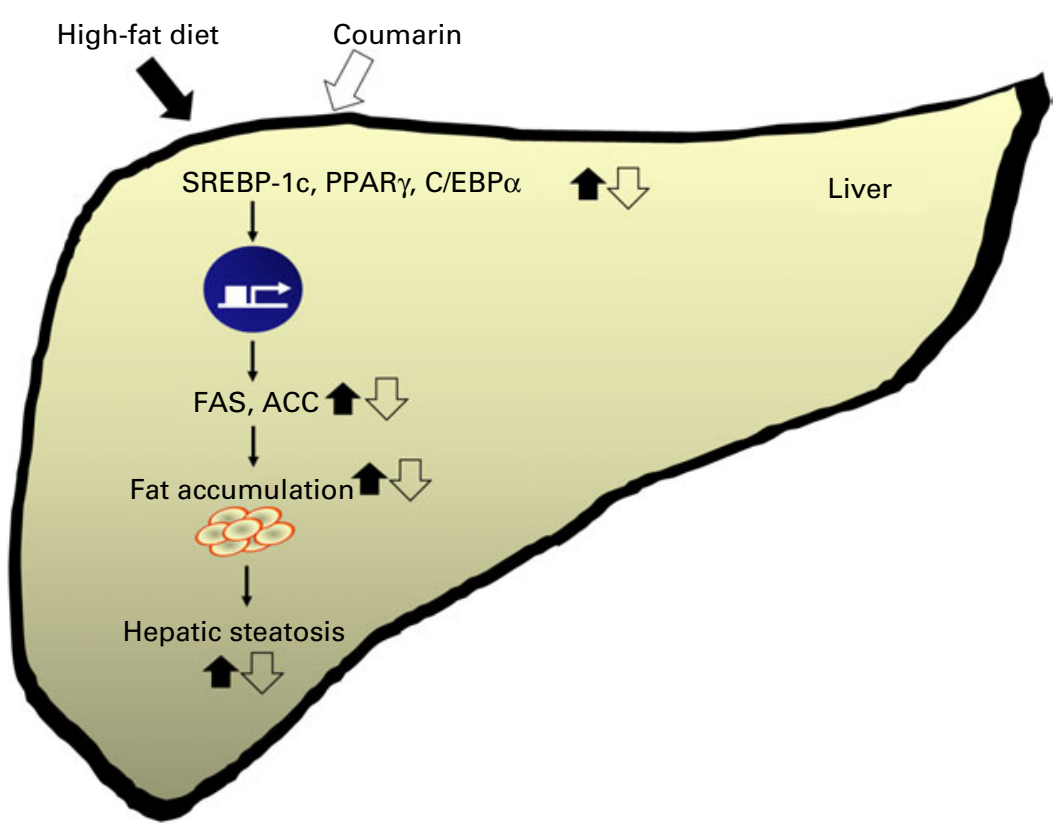

Fig. 5. Schematic diagram illustrating the effects of coumarin on high-fat diet-induced hepatic steatosis. Coumarin suppresses hepatic fat accumulation by regulating the expression of lipogenic genes. SREBP-1c, sterol regulatory element-binding protein-1c; C/EBP $\alpha, C C A A T / e n h a n c e r$ binding protein- $\alpha$; FAS, fatty acid synthase; ACC, acetyl-CoA carboxylase. (A colour version of this figure can be found online at http://www.journals.cambridge.org/bjn).

mice, thus promoting hepatic steatosis ${ }^{(4)}$. In the present study, we examined the effects of coumarin on PPAR $\gamma$ and $\mathrm{C} / \mathrm{EBP} \alpha$ protein levels in the liver. We found that HFD induced the up-regulation of PPAR $\gamma$ and $\mathrm{C} / \mathrm{EBP} \alpha$ in the liver, and courmarin clearly reduced those changes. Consistent with these results, hepatic lipid levels were also significantly decreased by coumarin. These data indicate that the protective effect of courmarin against hepatic steatosis can be mediated, at least in part, by PPAR $\gamma$ - and $\mathrm{C} / \mathrm{EBP} \alpha$-mediated lipogenic signalling.

On the other hand, another study reported that a HFD increases serum NEFA concentrations, which inhibits insulin signalling ${ }^{(31)}$. Insulin activates the transcription of SREBP-1c and PPAR $\gamma$, inducing lipogenesis ${ }^{(32)}$. We showed that reduced serum insulin levels coincided with lower SREBP-1c and PPAR $\gamma$ expression in mice treated with coumarin. Adiponectin is an adipose-derived hormone, and it could confer protective effects against hepatic steatosis via reduction of SREBP-1c and activation of AMP-activated protein kinase and PPAR $\alpha^{(33)}$. In addition, adiponectin enhances insulin sensitivity that results in the increase of glucose uptake and fatty acid oxidation in the liver ${ }^{(34)}$. Although we did not determine adiponectin in the present study, our findings suggest that the effect of courmarin was mediated, in part, by regulating insulin and adiponectin levels. As summarised in Fig. 5, coumarin represses the lipogenic pathway by down-regulating SREBP$1 c, \operatorname{PPAR} \gamma$ and $\mathrm{C} / \mathrm{EBP} \alpha$, which reduces the rate of hepatic fat accumulation.

In conclusion, we have demonstrated that coumarin protects against HFD-induced hepatic steatosis, which appears to be mediated through the regulation of genes involved in lipogenesis. These results suggest that coumarin may be useful in the alleviation of hepatic steatosis.

\section{Acknowledgements}

The present work was supported by the National Platform Technology Project from Ministry of Knowledge Economy and the Korea Food Research Institute. M. Y. U. performed the experimental work, acquisition of the data, analysis and wrote the original manuscript. M. K. M. and J. A. carried out the experiments. T. Y. H. designed the research and performed substantial editing. All authors reviewed the literature and contributed to the final report. The authors declare that there are no conflicts of interests.

\section{References}

1. Park HJ, Lee JY, Chung MY, et al. (2012) Green tea extract suppresses NFkB activation and inflammatory responses in diet-induced obese rats with nonalcoholic steatohepatitis. J Nutr 142, 57-63.

2. Farrell GC \& Larter CZ (2006) Nonalcoholic fatty liver disease: from steatosis to cirrhosis. Hepatology 43, S99-S112.

3. Assy N, Nassar F, Nasser G, et al. (2009) Olive oil consumption and non-alcoholic fatty liver disease. World J Gastroenterol $\mathbf{1 5}$, 1809-1815.

4. Park S, Choi Y, Um SJ, et al. (2011) Oleuropein attenuates hepatic steatosis induced by high-fat diet in mice. J Hepatol 54, 984-993.

5. Murat Bilgin H, Atmaca M, Deniz Obay B, et al. (2011) Protective effects of coumarin and coumarin derivatives against carbon tetrachloride-induced acute hepatotoxicity in rats. Exp Toxicol Pathol 63, 325-330.

6. Atmaca M, Bilgin HM, Obay BD, et al. (2011) The hepatoprotective effect of coumarin and coumarin derivates on carbon tetrachloride-induced hepatic injury by antioxidative activities in rats. J Physiol Biochem 67, 569-576. 
7. Hsu CL \& Yen GC (2007) Effects of flavonoids and phenolic acids on the inhibition of adipogenesis in 3T3-L1 adipocyte. J Agric Food Chem 55, 8404-8410.

8. Yuce B, Danis O, Ogan A, et al. (2009) Antioxidative and lipid lowering effects of 7,8-dihydroxy-3-(4-methylphenyl) coumarin in hyperlipidemic rats. Arzneimittelforschung 59, $129-134$.

9. Madhavan GR, Balraju V \& Mallesham B (2003) Novel coumarin derivatives of heterocyclic compounds as lipidlowering agents. Bioorg Med Chem Lett 13, 2547-2551.

10. Hsu CL, Wu CH, Huang SL, et al. (2009) Phenolic compounds rutin and o-coumaric acid ameliorate obesity induced by high-fat diet in rats. J Agric Food Chem 57, 425-431.

11. Cho SJ, Jung UJ \& Choi MS (2012) Differential effects of low-dose resveratrol an adiposity and hepatic steatosis in diet-induced obese mice. Br J Nutr 108, 2166-2175.

12. Samuel VT, Liu ZX, Qu X, et al. (2004) Mechanism of hepatic insulin resistance in non-alcoholic fatty liver disease. $J$ Biol Chem 279, 32345-32353.

13. Oosterveer MH, Van Dijk TH \& Tietge UJF (2009) High fat feeding induces hepatic fatty acid elongation in mice. PLOS One 4, e6066.

14. Pari L \& Rajarajeswari N (2009) Efficacy of coumarin on hepatic key enzymes of glucose metabolism in chemical induced type 2 diabetic rats. Chem Biol Interact 181, 292-296.

15. Ogawa H, Sasai N, Kamisako T, et al. (2007) Effects of osthol on blood pressure and lipid metabolism in stroke-prone spontaneously hypertensive rats. J Ethnopharmacol 112, $26-31$.

16. Folch H, Lees M \& Sloane Stanley GH (1957) A simple method for the isolation and purification of total lipides from animal tissues. J Biol Chem 226, 497-509.

17. Ohkawa H, Ohishi N \& Yagi K (1979) Assay for lipid peroxides in animal tissues by thiobarbituric acid reaction. Anal Biochem 95, 351-358.

18. Ochoa S (1955) Malic dehydrogenase from pig heart. In Methods in Enzymology, vol. 2, pp. 735-739 [SP Colowick and NO Kaplan, editors]. New York, NY: Academic Press.

19. Gibson DM \& Hubbard DD (1960) Incorporation of malonyl CoA into fatty acids by liver in starvation and alloxandiabetes. Biochem Biophys Res Commun 3, 531-535.

20. Lowry OH, Rosebrough NJ, Farr AL, et al. (1993) Protein measurement with the Folin phenol reagent. $J$ Biol Chem 193, 265-275.
21. Fried SK, Ricci MR, Russell CD, et al. (2000) Regulation of leptin production in humans. J Nutr 27, 79-82.

22. Min HK, Kapoor A, Fuchs M, et al. (2012) Increased hepatic synthesis and dysregulation of cholesterol metabolism is associated with the severity of nonalcoholic fatty liver disease. Cell Metab 15, 665-674.

23. Chatrath H, Vuppalanchi R \& Chalasani N (2012) Dyslipidemia in patients with nonalcoholic fatty liver disease. Semin Liver Dis 32, 22-29.

24. Araya J, Rodrigo R, Videla LA, et al. (2004) Increase in long-chain polyunsaturated fatty acid $n-6 / n-3$ ratio in relation to hepatic steatosis in patients with non-alcoholic fatty liver disease. Clin Sci (Lond) 106, 635-643.

25. Li J, Huang J, Li JS, et al. (2012) Accumulation of endoplasmic reticulum stress and lipogenesis in the liver through generational effects of high fat diets. J Hepatol 56, 900-907.

26. Mong MC, Chao CY \& Yin MC (2011) Histidine and carnosine alleviated hepatic steatosis in mice consumed high saturated fat diet. Eur J Pharmacol 653, 82-88.

27. Tessari P, Coracina A, Cosma A, et al. (2009) Hepatic lipid metabolism and non-alcoholic fatty liver disease. Nutr Metab Cardiovasc Dis 19, 291-302.

28. Yu S, Matsusue K, Kashireddy P, et al. (2003) Adipocytespecific gene expression and adipogenic steatosis in the mouse liver due to peroxisome proliferator-activated receptor gamma1 (PPARgamma1) overexpression. J Biol Chem 278, 498-505.

29. Inoue M, Ohtake T, Motomura W, et al. (2005) Increased expression of PPARgamma in high fat diet-induced liver steatosis in mice. Biochem Biophys Res Commun 336, 215-222.

30. Matsusue K, Gavrilova O, Lambert G, et al. (2004) Hepatic CCAAT/enhancer binding protein alpha mediates induction of lipogenesis and regulation of glucose homeostasis in leptin-deficient mice. Mol Endocrinol 18, 2751-2764.

31. Boden G \& Shumlaman GI (2002) Free fatty acids in obesity and type 2 diabetes: defining their role in the development of insulin resistance and beta-cell dysfunction. Eur J Clin Invest 32, 14-23.

32. Kahn SE, Hull RL \& Utzschneider KM (2006) Mechanisms linking obesity to insulin resistance and type 2 diabetes. Nature 444, 840-846.

33. You M \& Rogers CQ (2009) Adiponectin: a key adipokine in alcoholic fatty liver. Exp Biol Med (Maywood) 234, 850-859.

34. Lihn AS, Pedersen SB \& Richelsen B (2005) Adiponectin: action, regulation and association to insulin sensitivity. Obes Rev 6, 13-21. 